\title{
ANALISA EFEKTIFITAS PEMBELAJARAN BAHASA INGGRIS ANTARA METODE IN-CLASS DENGAN METODE SELF LEARNING DENGAN MEDIA KOMPUTER
}

\author{
Ari Setyorini \\ Jurusan Psikologi, Fakultas Psikologi, Bina Nusantara University \\ Jln. Kemanggisan Ilir III No. 45, Kemanggisan, Palmerah, Jakarta Barat 11480
}

\begin{abstract}
The purpose of this study was to measure the effectiveness of learning English between the methods inclass with a method of self-learning using computer aids and operational support staff in an international school. The research method used is descriptive method with a final score comparing between learning results and analyze how the increased English proficiency. A gap still exists in terms of English language proficiency for the operational support staff, we conducted this training program in the classroom with instructors as mentors and teachers in the learning process. And due to busy work schedules and shift changes are different, this learning program made independently by using a computer. The participants who experienced an increase in value is only one person or $6.67 \%$. With these results it may be concluded that a training program with the guidance of instructors in the classroom are more effective and successful in providing a better ability than the self-learning program with the help of computers. Things that affect, among others, are motivation to learn, as seen from the low frequency of attendance at the laboratory (average 93.33\% attendance below the required number of attendance), for participants with secondary education level and lower, self-study programs does not seem to be effective, and computer media can not replace the function of a mentor or teacher.
\end{abstract}

Keywords: self learning, instructor based learning, training program

\begin{abstract}
ABSTRAK
Tujuan penelitian ini adalah ingin menjawab bagaimanakah tingkat efektifitas pembelajaran Bahasa Inggris antara metode in-class dengan metode self learning dengan menggunakan alat bantu computer pada staff pendukung operasional pada sekolah internasional X. Metode penelitian yang digunakan adalah dengan menggunakan metode deskriptif dengan membandingkan skor akhir hasil pembelajaran dan menganalisa berapa yang mengalami peningkatan kemampuan Bahasa Inggris. Dikarenakan masih adanya kesenjangan dalam hal kemampuan bahasa Inggris bagi para staff pendukung operasional, maka dilakukanlah program pelatihan yang dilakukan di dalam kelas dengan instruktur sebagai pembimbing dan guru pada proses pembelajaran tersebut. Dan dikarenakan kesibukan dan perubahan jadwal kerja shift yang berbeda-beda, maka untuk mengatasi hal tersebut dibuatlah program pembelajaran secara mandiri dengan menggunakan computer. Adapun peserta yang mengalami peningkatan nilai adalah satu orang atau 6.67\%. dengan hasil ini dapat disimpulkan bahwa program pelatihan dalam kelas dengan bimbingan instruktur lebih efektif dan berhasil memberikan kemampuan yang lebih baik daripada program pembelajaran mandiri dengan bantuan computer. Hal-hal yang mempengaruhi antara lain adalah motivasi belajar, yang dilihat dari frekuensi jumlah kehadiran di laboratoriun yang rendah (rata-rata 93.33\% jumlah kehadiran dibawah jumlah kehadiran yang dipersyaratkan), untuk peserta dengan tingkat pendidikan menengah dan bahkan rendah tampaknya tidak efektif apabila dilakukan program belajar mandiri, dan media computer tidak bisa menggantikan fungsi seorang pembimbing atau pengajar.
\end{abstract}

Kata kunci: pembelajaran mandiri, pembelajaran dengan instruktur, program pelatihan 


\section{PENDAHULUAN}

Sekolah internasional X telah berdiri sejak tahun 1998. Karena merupakan sekolah internasional, maka komunikasi yang dilakukan sehari-hari antara murid dengan guru, dan juga dengan karyawan (non-teaching staff) adalah menggunakan bahasa Inggris. Kondisi ini menuntut penguasaan Bahasa Inggris yang baik untuk semua guru dan juga staff non akademis. Namun pada saat ini masih dirasakan kesenjangan kemampuan bahasa Inggris antara staff pengajar staff pendukung dan staff support.

Staff support adalah staff pendukung operasional yang berada di bawah koordinasi Dpartment Building Management. Adapun tugas utamanya adalah memberikan pelayanan kepada semua pengguna gedung, antara lain ketersediaan ruangan yang nyaman, fasilitas belajar mengajar yang baik dan dapat berfungsi sesuai kebutuhan pengajaran. Sedangkan standar kemampuan Bahasa Inggris yang diperlukan bagi para staff pendukung sesuai dengan kompetensi yang dipersyaratkan adalah sebagai berikut:

Tabel 1 Kompetensi Bahasa Inggris Bagi Staff Pendukung

\begin{tabular}{|c|c|c|}
\hline Core Compenteny & Proficiency Level * & Key behavior \\
\hline English Proficiency & Level 1 & $\begin{array}{l}\text { Listen and speaks in daily conversational English } \\
\text { Key actions samples: } \\
\text { - Greets others with "Good Morning, Sir”; "How are you” } \\
\text { - Answers simple questions such as address, name of person, } \\
\text { telephone number } \\
\text { - Understand core of the question, such as the person who is being } \\
\text { looked for }\end{array}$ \\
\hline English Proficiency & Level 1 & $\begin{array}{l}\text { Listen, Speak, Read and write in simple vocational English context } \\
\text { Key actions sample: } \\
\text { - Understand the short English sentences in working context with } \\
\text { simple words such as "make a copy of this", "meet me at } 11 \\
\text { tomorrow morning” } \\
\text { - Understand "ASAP”, “Ms/Sir/Mdm" } \\
\text { - Uses expression such as "I'm busy” instead of"I'm tied up”; or "I } \\
\text { don't know" instead of "I have no idea”. }\end{array}$ \\
\hline
\end{tabular}

Untuk memenuhi standar kemampuan kompetensi tersebut, yang ditemukan sebagai performance gap, maka dibentuklah program pengembangan yang berupa pelatihan dan juga program reinforcement berupa program belajar mandiri dengan bantuan computer (Computer Assisted Language Learning atau disingkat CALL) dengan bantuan software XXY yang telah disarankan oleh beberapa pakar pendidik Bahasa Inggris.

Oleh karena itu, maka (jumlah peserta) diikutkan dalam program pelatihan Bahasa Inggris selama 13 kali pertemuan dan difasilitasi oleh instruktur. Dan dikarenakan jadwal kerja yang beragam dengan shift yang berbeda-beda, maka sebagai program reinforcement, atau memperkaya pembelajaran, maka dibuatlah program self learning dengan menggunakan bantuan computer dan XXY yang dilakuakn di laboratorium bahasa, dimana setiap peserta dapat bebas belajar di sana sesuai dengan waktu luang yang ada. Adapun kehadiran instruktur hanya dilakuan pada pertemuan pertama, pertengahan program, dan akhir program, dengan sesi mentoring.

Dengan pemberian program yang berbeda ini, penulis ingin meneliti tingkat efektivitas antara program belajar di kelas dengan program belajar mandiri dengan menggunakan media computer pada pembelajaran bahasa Inggris pada staff pendukung tersebut. 


\section{Dasar Teori}

\section{Metode Pembelajaran}

Dalam proses pembelajaran, seorang guru / instruktur harus mampu memilih metode yang tepat, efektif dan sesuai dengan materi serta karakteristik siswa yang diajar. Sumitro et al (2004) mengemukakan bahwa sesuai dengan bentuk pendidikan demokratis, antara pengajar dan pembelajar mempunyai kedudukan yang seimbang, sehingga metode pendidikan yang digunakan lebih mengarah pada metode diskusi, tanya jawab, pemberian tugas, problem solving, dan berjalan dalam suasana yang dialogis.

Robert (2002) menyebutkan bahwa pada pembelajaran bahasa, dikenal ada empat metode pembelajaran, yaitu: (1) Metode tradisional (la méthode traditionnelle); (2) Metode langsung (la méthode directe); (3) Metode audio dan audiovisual (les méthodes audio-orale et audiovisuelle); (4) Metode yang lahir dari pendekatan komunikatif (les méthodes fondées sur l'approche communicative).

Menurut Robert (2002) metode yang lahir dari pendekatan komunikatif dapat jelaskan sebagai berikut: "les méthodes fondées sur l'approche communicative, elles visent à doter l'apprenant d'une compétence communicative pour le rendre autonome en centrant sur lui leur enseignement”. Metode yang lahir seiring dengan pendekatan komunikatif ini sering digunakan dalam pengajaran bahasa asing. Adapun metode ini ditujukan untuk melengkapi pembelajar, sebuah ketrampilan yang komunikatif untuk memberi kemandirian sambil memusatkan pengajaran kepadanya.

\section{Media Pembelajaran Bahsa Inggris dan Implementasinya}

Kata media berasal dari bahasa latin dan merupakan bentuk jamak dari medium yang secara harfiah berarti perantara atau pengantar atau pengantar pesan dari pengirim ke penerima pesan. Banyak batasan yang diberikan orang tentang media. Asosiasi Teknologi dan Komunikasi Pendidikan di Amerika misalnya membatasi media sebagai segala bentuk dan saluran yang digunakan orang untuk menyalurkan pesan/informasi. Gage \& Barliner (1977) menyatakan bahwa media adalah berbagai jenis komponen dalam lingkungan siswa yang dapat merangsangnya untuk belajar. Sementara itu Briggs (1977) berpendapat bahwa media adalah segala alat fisik yang dapat menyajikan pesan serta merangsang siswa untuk belajar.

Agak berbeda dari itu semua adalah batasan yang diberikan oleh National Education Association (NEA). Dikatakan bahwa media adalah bentuk-bentuk komunikasi baik tercetak maupun audiovisual serta peralatannya. Apapun batasan yang diberikan, ada persamaan-persamaan yang dapat dikombinasikan bahwa media adalah segala sesuatu yang dapat digunakan untuk menyalurkan pesan dari pengirim ke penerima sehingga dapat merangsang pikiran, perasaan, perhatian dan minat serta perhatian siswa sedemikian rupa sehingga proses belajar terjadi. (Sadiman \& Raharjo, 2002)

\section{Fungsi media}

Media dapat digunakan untuk mengatasi rasa kebosanan siswa; jika siswa tertarik dengan apa yang mereka kerjakan, mereka akan menikmati proses belajar mengajar dan memahami materi yang diberikan (Ur, 1988). Hal senada juga diungkapkan oleh DePorter dan Hernacki (2000) dalam bukunya Quantum Learning, bahwa media visual/alat peraga dapat menciptakan lingkungan yang optimal, baik secara fisik maupun mental. Hal yang terpenting adalah bahwa media mampu mendorong siswa untuk berbicara, menulis; dan dengan menggunakan media proses belajar mengajar dan hubungan antara guru-siswa akan terjalin lebih efektif.

Menurut Soekartiwi (1996), ada beberapa keuntungan yang dapat diraih dengan menggunakan media yaitu: (1) meningkatkan motivasi siswa; (2) mencegah kebosanan siswa dalam mengikuti suatu 
proses belajar mengajar ; (3) menjadikan proses belajar mengajar berjalan lebih sistematis; (4) memudahkan siswa memahami instruksi guru dalam proses belajar mengajar; dan (5) memperkuat pemahaman siswa pada konteks pelajaran yang diharapkan.

Dalam Sydney Micro Skill, media pembelajaran berfungsi untuk membangkitkan dan menjaga ketertarikan siswa, merangsang otak siswa untuk berfikir dengan landasan yang konkrit, dan mendapatkan tingkat pemahaman yang tinggi secara efisien dan tingkat permanensi dalam pembelajaran siswa. Namun demikian potensi besar media itu masih kurang dioptimalkan kegunaannya oleh para guru. Beberapa guru masih memiliki "psychological rejection" dalam penggunaannya dan kurang terampil dalam implementasinya disebabkan minimnya pelatihan yang dapat diikuti.

\section{Penggunaan Komputer dan Internet}

Kebanyakan guru di Indonesia masih jarang menggunakan komputer sebagai bantuan dalam proses pembelajaran. Penggunaan kapur dan papan tulis tampaknya masih mendominasi dalam penggunaan media pembelajaran. Tapi sekarang ini kita dihadapkan pada penemuan teknologi informasi yang telah berperan mempercepat putaran informasi. Tidaklah bijaksana bila kita menutup mata dengan berbagai penemuan yang sebenarnya memiliki nilai yang berharga untuk pembelajaran yang efektif. Bila kita ingin terus meningkatkan profesionalisme dan menjaga keberadaan kita agar tidak "usang", maka kita harus adaptif terhadap berbagai irama perubahan yang memang semakin cepat ini.

Dalam implementasinya memang perlu adanya dukungan dari manajemen sekolah untuk mengadakan laboratorium komputer. Di kota-kota besar, misalnya Jakarta, komputer sudah bukan sesuatu yang mewah. Siswa-siswa di kota besar juga relatif well-experienced dengan komputer sebagi alat bantu dalam berbagai hal. Ada tiga model penggunaan komputer dalam pengajaran bahasa, yaitu sebagai guru bahasa, sebagai perangsang percakapan, dan sebagai alat bantu untuk pengembangan ranah kognitif. Dalam memahami penggunaan komputer di ruang kelas, perlu diingat dua istilah penting, CAI dan CALL. Computer Assisted Instruction (CAI) merupakan istilah yang digunakan untuk mendeskripsikan program komputer yang didesain untuk pengajaran, sedangkan Computer Assisted Language Learning (CALL) merupakan istilah yang digunakan dalam pengajaran bahasa yang dilengkapi dengan penggunaan komputer.

Dalam menggunakan program CAI, siswa mengikuti instruksi pelajaran yang dikeluarkan dari tiap bagian tatkala berinteraksi dengan komputer. Biasanya digunakan untuk pengembangan keterampilan membaca dan menulis, pelajar dapat mencakup drill dan latihan-latihan praktis, lembar pemahaman wacana, game, simulasi dan sebagainya. Dalam perkembangannya sekarang ini, hardware terus mengalami kemajuan dengan menghasilkan fasilitas grafik yang lebih tajam, resolusi warna, penggunaan animasi, touch screen, tampilan video, keluaran audio, dan multimedia. Latihan-latihan listening komprehension telah dikembangkan dengan menggunakan sound blaster dan CD-ROM. Sebuah dialog dapat ditampilkan di layar (dan siswa dapat mendengarkannya), kemudian beberapa pertanyaan yang terkait dapat dilihat di layar. Saat itu juga siswa dapat melihat sebuah jawaban, sistem akses yang cepat dan akurat memungkinkan adanya balikan terhadap siswa secara real time.

Kajian lain menyatakan bahwa peningkatan kemampuan bahasa Inggris sebagai bahasa asing dapat dilakuakan degan berbagai cara, salah satunya adalah dengan memberikan pelatihan dan juga self learning menggunakan soft ware menggunakan media komputer. Definisi dari pelatihan adalah suatu keadaan yang dikondisikan untuk melatih para peserta dalam bentuk simulasi dan materi dengan tujuan untuk meningkatkan kemampua dan keterampilan yang dimiliki oleh peserta.

Disisi lain juga ditemukan bahwa training adalah pelatihan yang dilakukan untuk mengajarkan dan menambah kemampuan peserta berdasarkan spesifikasi materi tertentu yang 
masih berada dalam kategori tingkatan yang rendah, dengan tujuan setelah training dilakukan maka peserta dapat menambah kemampuan mereka dalam bidang tertentu dan mengaplikasikannya dalam pekerjaan mereka (Schultz \& Schultz, 2006). Training dapat juga mempunyai definisi sebagai salah satu tindakan khusus yang dilakukan oleh perusahaan atau organisasi untuk memfasilitasi karyawan mereka agar dapat meningkatkan kinerja dan kompetensi mereka dalam beraktivitas (Noe, 2008). Kompetensi dalam konteks ini mencakup pengetahuan, kemampuan dan tingkah laku yang dapat menunjang keberhasilan dalam suatu organisasi (Hollenbeck, 2008).

Melalui beberapa definisi diatas dapat kita ketahui bahwa kegiatan training adalah suatu kegiatan yang tidak hanya memerlukan materi dan simulasi sebagai pendukung dari proses training, tetapi juga memerlukan unsur traineeryang terlatih dan anggaran dana untuk menunjang kegiatan kegiatan yang dilakukan selama proses training ini. Saat ini training sudah menjadi komponen penting dalam perusahaan dan lembaga, industri pemerintahan dan kemiliteran (Schultz and Schultz, 2006). Argumen ini diperkuat dengan bukti - bukti terkini bahwa semakin banyaknya lembaga danorganisasi - organisasi yang bergerak dalam bidang raining, disisi lain sudah tidak menjadi rahasia umum lagi bahwa biaya untuk menyelenggarakan suatu training tidak dapat dikatakan murah atau cukup terjangkau (Schultz and Schultz, 2006).

Salah satu faktor yang menujang efektifitas pelatihan adalah memastikan kesiapan karyawan untuk mengikuti pelatihan, yang terdiri dari sikap dan motivasi, serta keterampilan dasar yang harus disiapkan. Hal-hal penting terkait dengan hal ini adalah tidak hanya para traineer yang menjadi unsur penting dari sebuah training, tetapi para peserta dari training pun menjadi salah satu unsur penting didalam pelaksanaannya, yaitu menunjuk kepada 2 hal yaitu : a) Kesiapan karyawan sebagai calon training secara mental (seperti dalam bentuk karakteristik mereka yang mencakup kemampuan, tingkah laku, kepercayaan dan motivasi mereka) yang nanti pada akhirnya dapat mereka terapkan dalam proses implementasi dilingkungan perusahaan; dan b) Dalam hal ini ternyata dukungan dari lingkungan setempat seperti fasilitas yang disediakan juga dapat membantu proses pelaksanaan training.

Secara keseluruhan dapat dikatakan bahwa kesiapan baik secara psikis dan psikologis dari calon peserta training siap. Hal ini dapat memicu motivasi belajar dari para calon peserta training untuk menambah kemampuan dasar mereka.Salah satu direktorat yang memerlukan peningkatan dalam kemampuan bahasa inggris adalah karyawan support yang terdiri dari staff Building Management dan staff Mechanical Engeenering. Kemampuan bahasa Inggris para staff tersebut memang masih rendah. Pada awalnya, program pengembangan bahasa Inngris ini dilakukan dengan metode di dalam kelas, dengan jadwal yang telah ditentukan. Namun dikarenakan jadwal mereka yang beragam dengan shift kerja yang berbeda-beda, maka untuk mengakomodasi keperluan pengembanan berbahasa Inggris dilakukan secara mandiri dengan metode Computer Assisted Language Learning (CALL) merupakan istilah yang digunakan dalam pengajaran bahasa yang dilengkapi dengan penggunaan komputer. Program ini dilakukan di dalam laboratorium bahasa dengan jadwal latihan yang fleksibel. Dengan dilakukannya kedua metode tersebut, peneliti ingin mengetahui bagaimanakan efektifitas pembelajaran bahasa Inggris dengan metode pelatihan di kelas dengan metode Computer Assisted Language Learning (CALL).

\section{METODE}

Metode penelitian yang digunakan adalah menggunakan motode eksperimen dan analisa data diskriptif. Sedangkan metode eksperimen yang dilakukan adalah dengan melakukan perlakuan pemberian pelatihan selama 3 bulan, yaitu dengan jadwal dimulai pada tanggal 29 Maret 2010 sampai dengan 23 Juni 2010. Pertemuan yang dilakukan adalah sebanyak 26 kali dengan waktu dimulai pada pukul 16.30 sampai dengan 18.10. Dan kemudian dilanjutkan dengan perlakuan pembelajaran dengan metode Computer Assisted Language Learning (CALL), yaitu dengan cara belajar bahasa inggris 
dengan menggunakan software dan untuk belajar peserta bisa melakukannya setiap saat dengan mengakses melalui laboratorium bahasa.

Diagram perlakuan yang diberikan adalah sebagai berikut:

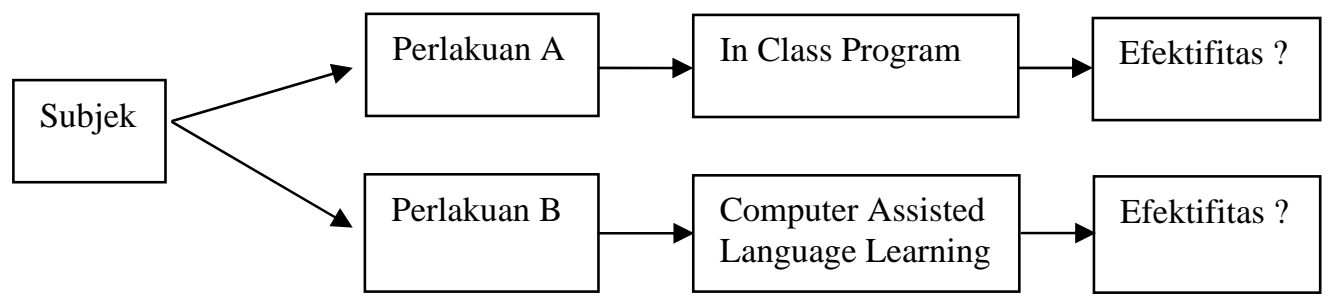

Gambar 1 Diagram perlakuan

Tujuan perlakuan berupa pelatihan adalah:

Membekali peserta dengan keterampilan dasar berbahasa Inggris, yaitu komunikasi verbal (speaking), kemampuan mendengarkan (listening), menulis (writing), membaca (reading), perbendaharaan kata (vocabulary), dan tata bahasa (grammar).

Data tentang peserta:

Terdiri dari 15 orang karyawan yang berada pada departemen yang sama, dengan job grade beragam, dengan frekuensi sebagai berikut:

Tabel 2 Distribusi Frekuensi Peserta

\begin{tabular}{ccccc}
\hline $\begin{array}{c}\text { Pendidikan } \\
\text { terakhir }\end{array}$ & Jumlah & Pendidikan terakhir & Jumlah & Prosentase \\
\hline SMA & 7 & & & \\
SMK & 3 & SMA dan sederajat & 14 & $93.33 \%$ \\
STM & 3 & & & \\
PGRI & 1 & D3 & 1 & $6.67 \%$ \\
D3 & 1 & S1 & 0 & $0.00 \%$ \\
S1 & 0 & & & \\
\hline
\end{tabular}

\section{Perlakuan A}

Semua subjek dimasukkan dalam satu kelas yang sama dengan materi pembelajaran pada tingkat menengah awal (pre-intermediate), dengan keterangan sebagai berikut:

Durasi setiap pertemuan : 100 menit

Jumlah pertemuan : 26 sesi yang terdiri dari:

- 21 sesi pembelajaran di kelas

- 1 sesi tes pertengahan

- 2 sesi tes akhir (tertulis dan oral)

- 2 sesi di laboraturioum bahasa 
Materi pembelajaran secara detail adalah sebagai berikut:

Tabel 3 Materi Pelatihan in-class

\begin{tabular}{|c|c|c|c|}
\hline Sesi & $\begin{array}{l}\text { Keterampilan yang } \\
\text { ditingkatkan }\end{array}$ & Topik & Materi \\
\hline 1 & Vocabulary & Karir & $\begin{array}{l}\text { Pembukaan } \\
\text { Perbendaharaan kata }\end{array}$ \\
\hline 2 & Reading & Karir & Membaca "10 cara untuk meningkatkan karir" \\
\hline 3 & Listening & & Request and offer \\
\hline 4 & Listening & & Telephone Skills \\
\hline 5 & Reading & Karir & Case Study "How to select candidates" \\
\hline 6 & Grammar \& Speaking & & Language Lab \\
\hline 7 & Vocabulary & Selling online & $\begin{array}{l}\text { Starting up } \\
\text { Vocabulary of Shopping }\end{array}$ \\
\hline 8 & Reading & $\begin{array}{l}\text { Selling } \\
\text { Online }\end{array}$ & $\begin{array}{l}\text { Reading "Worry for Retailers" } \\
\text { Language review of modals }\end{array}$ \\
\hline 9 & Speaking & $\begin{array}{l}\text { Selling } \\
\text { Online }\end{array}$ & Negotiation Skills \\
\hline 10 & Speaking & $\begin{array}{l}\text { Selling } \\
\text { Online }\end{array}$ & Negotiation Skills \\
\hline $\begin{array}{l}11 \\
12\end{array}$ & $\begin{array}{l}\text { Review Lessons } \\
\text { Mid Test }\end{array}$ & & \\
\hline 13 & Vocabulary & Companies & $\begin{array}{l}\text { Starting up } \\
\text { Vocabulary }\end{array}$ \\
\hline 14 & Listening & Companies & Listening \\
\hline 15 & Reading & & 'The world's most respected companies' \\
\hline 16 & Language Review & Companies & $\begin{array}{l}\text { Language review } \\
\text { Skills }\end{array}$ \\
\hline 17 & Language Lab & & \\
\hline 18 & Reading & Companies & Case study 'Valentino Chocolate' \\
\hline 19 & Listening & Great Ideas & $\begin{array}{l}\text { Starting up } \\
\text { Vocabularies } \\
\text { Listening }\end{array}$ \\
\hline $\begin{array}{l}20 \\
21\end{array}$ & Reading & $\begin{array}{l}\text { Great Ideas } \\
\text { Great Ideas }\end{array}$ & $\begin{array}{l}\text { Reading 'Three Great Ideas' } \\
\text { Language Review } \\
\text { Skills }\end{array}$ \\
\hline $\begin{array}{l}22 \\
23\end{array}$ & $\begin{array}{l}\text { AV Session } \\
\text { Review Lessons }\end{array}$ & & \\
\hline 24 & Final Test I & & Writing \\
\hline 25 & Final Test II & & Oral \\
\hline 26 & Report Card Day & & \\
\hline
\end{tabular}

Selama pelatihan berlangsung, peserta mendapatkan perlakuan evaluasi yaitu tes pertengahan, dan tes akhir dengan jadwal sebagai berikut:

Tabel 4 Jadwal perlakuan

\begin{tabular}{lll}
\hline NO & TANGGAL & KETERANGAN \\
\hline 1 & Mid Test & 5 Mei 2010 \\
2 & Final Test - Written & 16 Juni 2010 \\
3 & Final Test - Oral & 21 Juni 2010 \\
4 & Report Card Day & 23 Juni 2010 \\
\hline
\end{tabular}




\section{Perlakuan B}

Materi Pembelajaran self learning dengan metodenya adalah sebagai berikut:

Tabel 5 Materi Pembelajaran Self Learning

\begin{tabular}{cll}
\hline Sesi & \multicolumn{1}{c}{ Topic } & \multicolumn{1}{c}{ Metode } \\
\hline $1^{\text {st }}$ & Introducing Oneself (I) & Video, Reading, Pronunciation \\
$2^{\text {nd }}$ & Introducing Oneself (II) & Dialog, Exercise \\
$3^{\text {rd }}$ & Introducing Oneself (III) & Exercise \\
$4^{\text {th }}$ & Descriptions (I) & Video, Reading, Pronunciation \\
$5^{\text {th }}$ & Descriptions (II) & Dialog, Exercise \\
$6^{\text {th }}$ & Descriptions (III) & Exercise \\
$7^{\text {th }}$ & Numbers And Letters (I) & Video, Reading, Pronunciation \\
$8^{\text {th }}$ & Numbers And Letters (II) & Dialog, Exercise \\
$9^{\text {th }}$ & Numbers And Letters (III) & Exercise \\
$10^{\text {th }}$ & Mid Test & Testing Previous Materials \\
$11^{\text {th }}$ & Date And Time(I) & Video, Reading, Pronunciation \\
$12^{\text {th }}$ & Date And Time(II) & Video, Reading, Pronunciation \\
$13^{\text {th }}$ & Date And Time(III) & Exercise, Pronunciation \\
$14^{\text {th }}$ & Objects \& Animals (I) & Video, Reading, Pronunciation \\
$15^{\text {h }}$ & Objects \& Animals (II) & Dialog, Exercise, Pronunciation \\
$16^{\text {th }}$ & Objects \& Animals (III) & Exercise, Pronunciation \\
$17^{\text {th }}$ & Adjectives (I) & Video, Reading, Pronunciation \\
$18^{\text {th }}$ & Adjectives (II) & Dialog, Exercise, Pronunciation \\
$19^{\text {th }}$ & Adjectives (III) & Exercise, Pronunciation \\
$20^{\text {th }}$ & Review Session & Face to face meeting with the trainers \\
$21^{\text {st }}$ & Final Test & Testing Previous Materials \\
\hline & & \\
& &
\end{tabular}

Hasil perlakuan A dan B adalah sebagai berikut:

Tabel 6 Data Hasil Evaluasi

\begin{tabular}{llccccc}
\hline \multirow{2}{*}{ Peserta } & \multirow{2}{*}{ Job } & EEP & \multicolumn{5}{c}{ ESLP } \\
\cline { 2 - 7 } & Grade & Score & Grade & Level & Score & Grade \\
\cline { 2 - 7 } & Level & 68 & C & Beginner 1 & 60.5 & D \\
P 1 & Elementary 1 & 70 & C & Beginner 1 & 45.5 & F \\
P 2 & Elementary 1 & 70 & C & Beginner 1 & 41.5 & F \\
P 3 & Elementary 1 & 75 & B & Beginner 2 & 57.5 & D \\
P 4 & Elementary 1 & 73 & C & Beginner 2 & 60 & D \\
P 5 & Elementary 1 & 85 & A & Beginner 2 & 42.2 & F \\
P 6 & Elementary 1 & 67 & C & Beginner 2 & 52.7 & F \\
P 7 & Elementary 1 & 68 & C & Beginner 2 & 62.7 & D \\
P 8 & Elementary 1 & 70 & C & Beginner 2 & 42.3 & F \\
P 9 & Elementary 1 & 80 & B & Beginner 2 & 37.5 & F \\
P 10 & Elementary 1 & 72 & C & Beginner 2 & 57.3 & D \\
P 11 & Pre-Intermediate 1 & 68 & C & Beginner 2 & 57.2 & D \\
P 12 & Elementary 1 & 70 & C & Beginner 2 & 24 & F \\
P 13 & Elementary 1 & 82 & B & Advance 1 & 74 & C \\
P 14 & Pre-Intermediate 1 & 84 & B & Advance 2 & 87.2 & A \\
P 15 & Pre-Intermediate 1 & & & &
\end{tabular}


Adapun hasil observasi dari pelatihan terhadap para peserta adalah sebagai berikut:

Tabel 7 Data Frekuensi Kehadiran

\begin{tabular}{lcc}
\hline 26 kali kehadiran & 1 & $6.67 \%$ \\
dibawah 26 kali kehadiran & 14 & $93.33 \%$ \\
\hline
\end{tabular}

Tabel 8 Jumlah Total Waktu Pembelajaran Self Learning

\begin{tabular}{cccc}
\hline Peserta & Hadir & absen & Jam \\
\hline P 1 & 21 & 5 & 35 \\
P 2 & 24 & 2 & 40 \\
P 3 & 25 & 1 & 42 \\
P 4 & 21 & 0 & 35 \\
P 5 & 23 & 3 & 38 \\
P 6 & 23 & 3 & 38 \\
P 7 & 24 & 2 & 40 \\
P 8 & 26 & 0 & 43 \\
P 9 & 23 & 3 & 38 \\
P 10 & 23 & 3 & 38 \\
P 11 & 22 & 4 & 37 \\
P 12 & 13 & 13 & 22 \\
P 13 & 21 & 5 & 35 \\
P 14 & 24 & 2 & 40 \\
P 15 & 24 & 2 & 40 \\
\hline
\end{tabular}

Tabel 9 Rangkuman Jumlah Waktu Belajar

\begin{tabular}{lcc}
\hline & Jumlah & Prosentase \\
\hline Jumlah waktu dibawah standar & 1 & $6.6 \%$ \\
Jumah waktu sesuai standar & 3 & $20 \%$ \\
Jumlah waktu di atas standar & 11 & $73.3 \%$ \\
\hline
\end{tabular}

\section{HASIL DAN PEMBAHASAN}

Analisa hasil penelitian ini hanya difokuskan pada evaluasi peningkatan kemampuan antara pada saat mengikuti program dalam kelas dan pada saat mengikuti Computer Assisted Language Learning, dengan hasil analisa sebagai berikut:

Tabel 10 Data analisa hasil evaluasi

\begin{tabular}{lcc}
\hline \multicolumn{1}{c}{ Kriteria } & Frekuensi & Prosentase \\
\hline Skor mengalami peningkatan & 1 & $6.7 \%$ \\
Skor tetap & 0 & $0 \%$ \\
Skor mengalami penurunan & 14 & $93.3 \%$ \\
\hline
\end{tabular}


Dengan data tersebut dapat disimpulkan bahwa program self learning atau Computer Assisted Language Learning (CALL) ternyata tidak efektif dalam meningkatkan kemampuan Bahasa Inggris pagi para peserta. Dan terdapat 14 orang atau sebanyak 93.3\% yang mengalami penurunan kemampuan BerBahasa Inggris dibandingkan dengan hasil skor kemampuan Bahasa Inggris dari program dalam kelas (in-class) dengan proses belajar yang dibimbing oleh seorang guru atau instruktur.

Menggunakan komputer dalam pengajaran bahasa mampu memberikan berbagai jenis kegiatan dan potensi yang tidak terbatas. Namun Dari hasil tersebut dapat disimpulkan bahwa metode pembelajaran dengan program Computer Assisted Language Learning kurang efektif sebagai program lanjutan yang bertujuan untuk meningkatkan kemampuan bahasa inggrs secara mendiri.

Beberapa faktor yang dapat menjadi penyebab ketidakefektifan program ini antara lain adalah:

\section{Media Pembelajaran}

Pengajaran berbasis komputer dapatlah digunakan sebagai sumber daya di kelas, bukan menggantikan keberadaan guru / pengajar (http: media-pembelajaran-bahasa-inggris, 2010). Faktor social facilitation juga dapat mempengaruhi efektifitas pembelajaran. Social facilitation adalah kondisi dimana tingkat hasil kerja seseorang meningkat karena kehadiran orang lain (Hughes, Ginnet, dan Curphy, 2009). Sebagaimana diketahui bahwa pada program Computer Assisted Language Learning proses pembelajaran tidak dibimbing secara langsung oleh instruktur.

\section{Tingkat Pendidikan}

Tingkat computer literacy berkaitan dengan self efficacy yang kemungkinan rendah. Self efficacy adalah suatu kondisi dimana seseorang merasa percaya diri bahwa mereka mempunyai kemampuan untuk melakukan hal-hal yang harus dilakukan (Hughes, Ginnet, dan Curphy, 2009).

\section{Tingkat Kedisiplinan}

Berdasarkan data yang ada, dimana telah ditentukan minimal total waktu yang diperlukan untuk menguasai suatu unit materi adalah 93.33\% dibawah yang dipersyaeartan. Bagi kemampuan yang meningkat adalah terjadi pada P 15, dimana Sikap positif ini tampaknya sangat mendukung mereka untuk memdapatkan skor nilai yang tinggi dan mencapai skor A untuk kedua kemampuan, baik oral maupun written. Sedangkan faktor pendukung kesuksesan mereka adalah bahwa mereka telah mempunyai dasar pengetahuan yang lebih baik dibandingkan dengan peserta lain (dilihat dari hasil placement test), sehingga hal ini sangat membantu mereka dalam memahami materi yang dipelajari.

\section{PENUTUP}

Kesimpulan yang didapatkan dari penelitian ini adalah bahwa hanya 6.7\% dari jumlah subjek yang mengalami peningkatan kemampuan berbahasa inggris dan terdapat 93.3\% subyek tidak mengalami peningkatan kemampuan yang signifikan dari hasil kemampuan bahasa inggris dengan pogram Computer Assisted Language Learning. Berdasarkan pembahasan di atas, dapat disimpulkan bahwa program pelatihan bahasa inggris akan efektif bila dilaksanakan pada tingkat yang sesuai dengan tingkat kemampuan peserta serta perlu didukung oleh faktor-faktor psikologis dalam proses belajar orang dewasa, yaitu motivasi belajar yang tinggi, dimana hal ini akan mempengaruhi keaktifan peserta pada proses brlajar, serta self efficacy yang tinggi, dimana hal ini akan mempengaruhi kepercayaan diri para peserta dalam mempelajari materi bahas asing. Kedua faktor tersebut sangat penting untuk menunjang eektifitas pembelajaran dikarenakan belajar bahasa asing memerlukan faktor kemauan belajar yang tinggi serta keaktifan dalam berlatih bahasa yang dipelajari. 
Apabila program ini akan dilanjutkan kepada peserta yang sama, rekomendasi untuk pelaksanaan program selanjutnya adalah untuk memberikan materi tambahan tentang kemampuan tertulis (written) kepada peserta pada kelompok A, dan diujikan kembali sampai mereka berada pada tingkat kemampuan yang sama, minimal dengan skor B. Rekomedasi lain yang bisa dilakuakan, sesuai dengan pendapat dari Gerhard (2008) untuk membuat program pelatihan efektif, perlu dibuat suatu lingkungan pembelajaran yang mendukung (creating learning environment), salah satunya dengan diberikan kesempatan untuk menerapkan apa yang sudah mereka pelajari atau akrab disebut dengan praktek lapangan didalam bidang tertentu sesuai dengan pengetahuan dan keterampilan yang sedang dipelajari dan ingin ditingkatkan. Prospek pengembangan penelitian dari hasil penelitian ini adalah penerapan tingkatan program pelatihan bagi para karyawan, agar hasil pembelajaran menjadi lebih efektif, tidak hanya sekedar terdapat pengaruh peningkatan kemampuan, namun pada analisa apakah standar kemampuan yang harus dimiliki tercapai atau tidak. Aplikasi lebih jauh dari penelitian ini adalah dianalisa tentang pengaruh latar belakang pendidikan dan metode pembelajaran yang dikaitkan dengan kaidah pembelajaran orang dewasa terhadap efektivitas pembelajaran bahasa asing.

\section{DAFTAR PUSTAKA}

Briggs, L.J. (ed.) (1977). Instructional Design: Principles and Applications New Jersey: Englewood Cliffs.

DePorter, B., \& Hernacki, M. (2000). Quantum Learning. Boston: Allyn and Bacon

Gage, N.L., Barliner, D. C. (1977). Educational Psychology. Chicago: Rand McNally.

Hollenbeck, G. P. (2008) Executive selection-What's right...and what's wrong. Industrial and Organizational Psychology. Perspective on Science and Practice. Vol 2(2), Jun 2009, 130143.

Noe, R. A. (2008). Employee Training and Development, $4^{\text {th }}$ Edition. Irwin.

Robert, J. P. (2002). Dictionaire Pratique de Didactique du FLE. Paris: OPHRYS.

Sadiman, A, \& Raharjo, R. (2002) Media Pendidikan: Pengertian, Pengembangan dan Pemanfaatannya. Jakarta: RajaGrafindo Persada.

Schultz, D., \& Schultz, S. E. (2006), Psychology \& Work Today, Ninth Edition, Pearson.

Soekartiwi (1996). Rancangan Instruksional. Jakarta: RajaGrafindo Persada.

Sumitro et. al. (2004). Pengantar Ilmu Pendidikan. Yogyakarta: FIB UNY.

Ur, P. (1988). Grammar Practice Activities. New York: Cambridge University Press

\section{RIWAYAT PENULIS}

Ari Setyorini lahir di kota Wonosobo pada 17 Desember 1975. Penulis menamatkan pendidikan S1 di Universitas Gadjah Mada dalam bidang Psikologi pada tahun 2001, menamatkan pendidikan S2 di Universitas Indonesia dalam bidang Psikologi Terapan bidang Sumber Daya Manusia pada tahun 2006. Saat ini bekerja sebagai Learning and Development Manager di Bina Nusantara. 